УДК 543.544:547.913

\title{
ИЗУЧЕНИЕ ЗАВИСИМОСТИ АНТИОКСИДАНТНОЙ АКТИВНОСТИ ЭФИРНЫХ МАСЕЛ КОРИАНДРА, ИМБИРЯ, СЕМЯН ТМИНА И РОЗОВОГО ГРЕЙПФРУТА ОТ КОНЦЕНТРАЦИИ МАСЛА В СИСТЕМЕ МЕТОДОМ КАПИЛЛЯРНОЙ ГАЗОВОЙ ХРОМАТОГРАФИИ
}

\author{
(С) А.Л. Самусенко \\ Институт биохимической фризики им. Н.М. Эмануэля РАН, ул. Косыгина, 4, \\ Москва, 119991 (Россия), e-mail: Samusenko.alexey@rambler.ru
}

\begin{abstract}
Методом капиллярной газожидкостной хроматографии исследована зависимость величины антиоксидантной активности от концентрации в системе эфирных масел кориандра (Coriandrum sativum L.), имбиря (Zingiber officinale L.), семян тмина (Carum carvi) и розового грейпфрута (Citrus paradisi). Оценка антиоксидантных свойств проведена по реакции окисления транс-2-гексеналя в соответствующую карбоновую кислоту. Найдено, что зависимость величины антиоксидантной активности масел от их концентрации непосредственно связана со скоростью изменения содержания основных веществ-антиоксидантов в составе изученных эфирных масел при длительном хранении на свету. Отмечено, что величина активности основных соединений, входящих в состав изученных масел, оказывает заметное влияние на концентрационную зависимость антиоксидантой активности масел в целом. Наиболее сильную зависимость антиоксидантной активности от концентрации наблюдали для масла кориандра, а наименее - для масла имбиря. Низкие концентрации масла розового грейпфрута не оказывали ингибирующего действия на окисление тест-альдегида.

Ключевые слова: пряно-ароматические растения, эфирные масла, антиоксидантная активность, капиллярная газовая хроматография.
\end{abstract}

\section{Введение}

В последнее время в результате многочисленных исследований установлена биологическая активность эфирных масел пряно-ароматических растений, в том числе - антиоксидантная [1-7]. Поскольку пряно-ароматические растения являются источниками природных антиоксидантов, использование их эфирных масел представляет альтернативу синтетическим антиоксидантам, которые потенциально опасны для здоровья человека [8-9]. Поэтому изучение антиоксидантной активности (АОА) эфирных масел пряноароматических растений является важной задачей для косметической химии, ароматерапии, пищевой и парфюмерной промышленности.

Биологическая активность эфирных масел зависит от их состава. Обнаружено, что сильными антибактериальными и АО свойствами обладают эфирные масла, содержащие замещенные фенолы - эвгенол, тимол, карвакрол и гваякол [10-15]. Относительно недавно предложены компьютерные программы, позволяющие предсказать АОА 32 эфирных масел, используя данные о составе их активных компонентов [16].

Ранее на примере окисления альдегидов мы провели сравнительную оценку АОА эфирных масел, содержащих в своем составе монотерпены ( $\gamma$-терпинен и $\alpha$-терпинолен), сесквитерпены (зингиберен и $\beta$-кариофиллен) и цитраль, которые также обладают высокой АОА [17-18]. Однако концентрация масел в системе «альдегид - эфирное масло» была достаточно высока, а исследования при других значениях концентрации масла не проводили. В связи с этим было интересно изучить влияние концентрации обладающих АОА

Самусенко Алексей Леонидович - научный сотрудник, тел.: (499) 135-78-94, e-mail: Samusenko.alexey@rambler.ru эфирных масел на скорость окисления альдегида и сопоставить полученные результаты с количественным изменением состава активных компонентов масел. 
Цель работы - изучить зависимость АОА эфирных масел кориандра, имбиря, семян тмина и розового грейпфрута от их концентрации в системе и соотнести полученные данные с изменением содержания основных веществ-антиоксидантов, входящих в состав масел.

\section{Экспериментальная часть}

Исследовали свежие образцы эфирных масел: кориандра (Coriandrum sativum L.), имбиря (Zingiber officinale L.) («Plant Lipids Ltd.», Индия), семян тмина (Carum carvi) («Lionel Hitchen», Великобритания) и розового грейпфрута (Citrus paradisi) («Frutarom», Израиль).

Для оценки АО свойств эфирных масел и их смесей в 50 мл $H$-гексана растворили 400 мкл транс-2гексеналя и 400 мкл $н$-додекана (8 мкл/мл); последний служил внутренним стандартом. Раствор разделили на аликвоты по 2 мл, которые поместили в стеклянные пробирки объемом 10 мл, и добавили по 200, 100, 50 или 20 мкл эфирных масел кориандра, имбиря, семян тмина и розового грейпфрута (всего 16 образцов). В контрольный образец масло не добавляли. Каждый образец был приготовлен двукратно. Образцы в закрытых пробками пробирках держали на свету при комнатной температуре в течение 145 сут. Источником света служило естественное освещение в лаборатории. Каждую неделю пробирки открывали и продували 10 мл воздуха с помощью пипетки. Количественное содержание гексеналя в пробирках определяли методом капиллярной газовой хроматографии через каждые 8-12 сут в первые 3 мес. хранения, а затем с интервалом в 1 мес. Изменения в составе эфирных масел фиксировали через 1, 2, 3, 4 и 5 мес. с начала хранения.

Газохроматографический анализ образцов эфирных масел проводили на хроматографе «Micromat412» фирмы «Nordion Instr.» (Финляндия) на кварцевой капиллярной колонке SPB-1 («Supelco», CША, 35 м $\times 0,32$ мм, толщина слоя фазы 0,25 мкм) при программировании температуры колонки от 60 до $250{ }^{\circ} \mathrm{C}$ со скоростью 8\%мин. Скорость газа-носителя гелия составляла 1 мл/мин, температура инжектора и пламенно-ионизационного детектора $-250{ }^{\circ} \mathrm{C}$. Идентификацию компонентов в образцах масел осуществляли на основе величин индексов удерживания путем их сопоставления с литературными [19] или экспериментальными данными, полученными нами. Количественное содержание гексеналя и компонентов эфирных масел рассчитывали по отношению площадей пиков, соответствующих веществам и внутреннему стандарту, содержание которого принимали кратным 8 мкл/мл. Степень окисления гексеналя и компонентов эфирных масел (отн.\%) определяли по отношению к их содержанию в исходных образцах.

\section{Результаты и обсуждение}

Для оценки АОА исследуемых эфирных масел мы использовали тест «альдегид/карбоновая кислота» [20]. Этот метод успешно применяли для проверки АО активности летучих экстрактов из различных растений, например, гвоздики, эвкалипта [21] и некоторых сортов зеленого и черного чая [22].

Тест-вещество и критерий для оценки АОА изучаемых масел были выбраны аналогично работе [17]. На рисунке 1 представлена зависимость АОА масел от их концентрации в системе «эфирное масло - альдегид». Как видно из рисунка 1, все исследованные масла обладали различной АО активностью. В контрольном растворе (К) период полуокисления (ПО) альдегида составлял 21 сут, в то время как наличие в растворе эфирных масел в той или иной степени ингибировало окисление альдегида, причем степень ингибирования зависела от их концентрации в системе.

При уменьшении концентрации масла с 10 до 5, 2.5 и 1 об.\% мы отмечали последовательное снижение АОА системы «альдегид - эфирное масло». Особенно резкое снижение АОА наблюдали на примере масла кориандра (рис. 1). В то время как при концентрации масла 10\% ПО гексеналя составлял 120 сут., в $1 \%$ масле эта величина не превышала 42 сут., то есть всего лишь в 2 раза превышала аналогичную величину в контрольном растворе. Иную картину наблюдали в случае масла имбиря, где аналогичные величины ПО составляли 75 и 45 сут. соответственно (рис. 1), то есть снижение АОА в том же диапазоне концентраций масла происходило менее резко. Поскольку основным компонентом эфирного масла кориандра является линалоол (65-75\%), мы проследили изменение его содержания в системе в процессе автоокисления масла (рис. 2). Как показано ранее [23], линалоол обладает слабо выраженной АОА. Вероятно, поэтому снижение его содержания при уменьшении концентрации масла в системе приводит к более выраженному уменьшению АОА эфирного масла кориандра по сравнению с другими изученными маслами. 
Наименее резкую зависимость АОА от концентрации имело эфирное масло имбиря. Основным компонентом (25-30\%) имбирного масла является зингиберен.

Это сесквитерпеновое соединение имеет достаточно выраженную АОА и склонно к осмолению при хранении масла. За время исследования содержание зингиберена в масле уменьшалось более чем в 30 раз. При этом наблюдали изменение запаха масла. Однако, как видно из рисунка 3, резкое падение содержания зингиберена в масле наблюдали только после 60 сут. процесса автоокисления, причем к этому времени даже в $1 \%$ масле имбиря оставалось неокисленным $15 \%$ вещества. Сравнение данных, полученных для эфирных масел кориандра и имбиря, показывает, что на зависимость АОА масел от их концентрации в сис-<smiles>CC(C)=CCCC(C)C1C=CC(C)=CC1</smiles>

Зингиберен теме оказывает влияние не только скорость изменения основного антиоксиданта в том или ином эфирном масле в процессе автоокисления, но и непосредственно величина АОА этих соединений.

Эфирное масло семян тмина по величине АОА сравнимо с маслом фенхеля [17]. ПО альдегида в обоих маслах составлял 54 сут для 10\% концентрации. Однако зависимость АОА от концентрации масла в системе в случае тмина выражена менее резко, чем для фенхеля. Если в масле фенхеля основным антиоксидантом являлся транс-анетол, окисление которого ускорялось при малых значениях концентрации масла в системе, то в масле тмина в качестве основных веществ выступают карвон, содержание которого достигает 50-60\%, и лимонен (около 30\%). На рисунке 4 представлена зависимость изменения содержания карвона в процессе автоокисления для различных концентраций масла семян тмина. Интересно отметить, что в данном случае происходит одновременно окисление и второго основного вещества - лимонена, причем одним из продуктов окисления последнего является тот же карвон.<smiles>C=C(C)C1CC=C(C)CC1C(=C)C1CC=C(C)C(=O)C1</smiles>

Очевидно, что при таком «конкурирующем» процессе уменьшение содержания карвона будет замедляться. Как видно из рисунка 4 , в $1 \%$ масле тмина остается неокисленным $15 \%$ вещества даже после 110 сут. процесса автоокисления.

Наименьшей величиной АОА из изученных масел обладало масло розового грейпфрута; величина ПО альдегида для 10\% масла составляла лишь 38 сут. Основным веществом в масле розового грейпфрута является лимонен (93-95\%). На рисунке 5 представлено изменение содержания лимонена для различных концентраций масла грейпфрута в процессе автоокисления. Скорость окисления лимонена в масле грейпфрута несколько выше, чем линалоола в масле кориандра (рис. 2 и 5). Несмотря на неполное окисление лимонена во всем изученном диапазоне концентраций (рис. 5), масло грейпфрута не ингибирует окисление альдегида при низких (менее 5 об.\%) концентрациях в системе (см. рис. 1). На примере индивидуальных компонентов различных эфирных масел и цитраля, взятого в качестве тест-альдегида, ранее показано [23], что лимонен не является сильным антиоксидантом, хотя не уступает линаоолу по величине АОА. С этой точки зрения, казалось бы, кориандровое и грейпфрутовое масла должны были обладать примерно одинаковой АОА. Однако масло кориандра, кроме основного вещества - линалоола, содержало около $2 \%$ сильного антиоксиданта - $\gamma$-терпинена, который не может не влиять на окисление линалоола и который полностью отсутствует в масле грейпфрута. Совершенно очевидно, что этим объясняется также существенное различие в величине АОА двух масел - кориандра и грейпфрута (величина ПО альдегида для $10 \%$ масел составляет 120 и 38 сут. соответственно, см. рис. 1). 

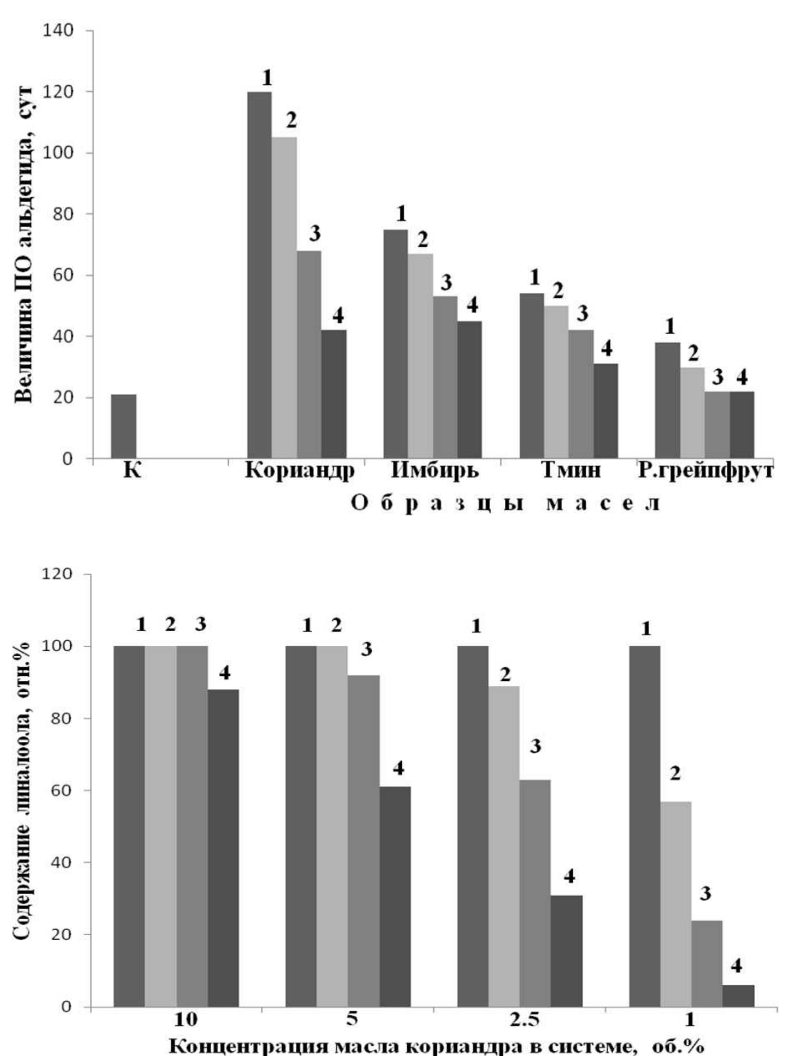

Рис. 2. Кориандр - линалоол

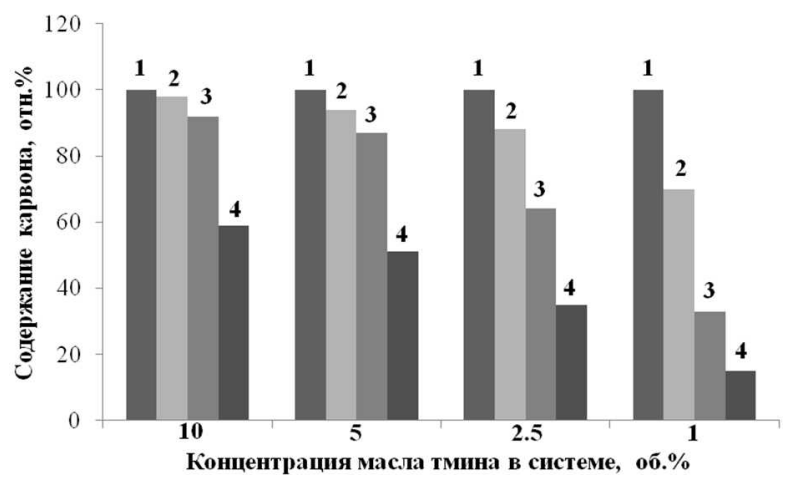

Рис. 4. Тмин - карвон
Рис. 1. Зависимость величины ПО транс-2гексеналя от концентрации эфирного масла в системе. Обозначения: К - контроль; концентрации масел: $1-10 \% ; 2-5 \% ; 3-2.5 \%$; 4-1\%

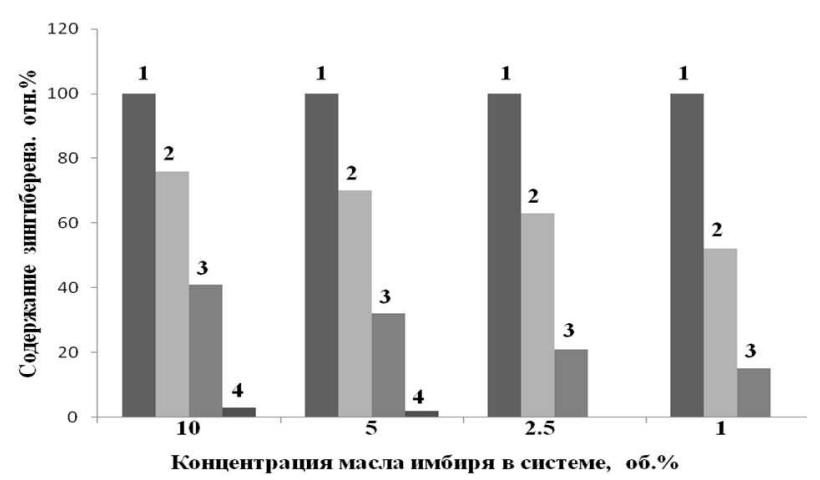

Рис. 3. Имбирь - зингиберен

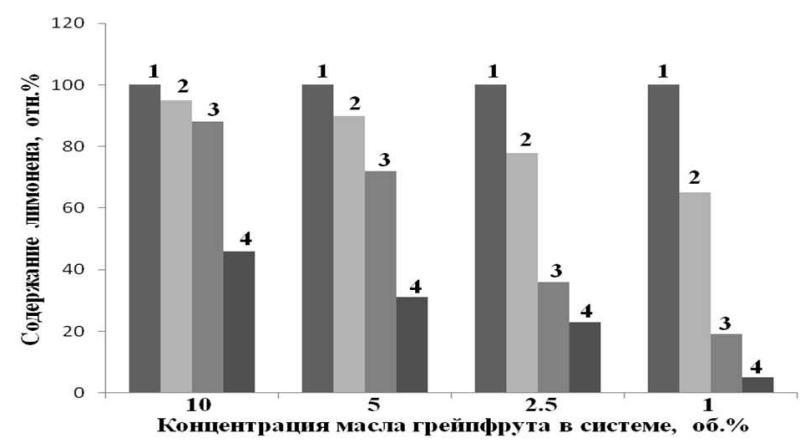

Рис. 5. Розовый грейпфрут - лимонен

Общая подпись к рисункам 2-5: Изменение содержания основных веществ - антиоксидантов в эфирных маслах при различных концентрациях масла в системе. Обозначения: 1 - 0; 2 - 30; 3 - 60; 4 - 110 сут процесса автоокисления

Следует отметить, что мы наблюдали резкое изменение запаха масла грейпфрута в процессе его автоокисления. Мы проследили за увеличением продуктов окисления лимонена в $10 \%$ масле грейпфрута: $\alpha$ терпинеола, карвона и эпоксилимонена (рис. 6). Как видно из графика на рисунке 6, после 60 сут. процесса автоокисления из всех трех продуктов наиболее резко происходило накапливание карвона. Окисление лимонена до карвона, по-видимому, сопровождается образованием воды, вследствие чего эфирное масло розового грейпфрута становилось мутным.

Таким образом, проведенное исследование показало, что величина АОА изученных эфирных масел находится в зависимости от их концентрации в системе, и эта зависимость индивидуальна для каждого масла. АОА всех масел понижается при уменьшении концентрации масла, причем характер этой зависимости связан со скоростью изменения содержания активных компонентов в составе масла в процессе автоокисления и величиной их исходной АОА. Знания о характере зависимости АОА того или иного масла от его концентрации позволяют целенаправленно регулировать стабильность систем, в которые эфирные масла входят в качестве ингредиентов. 
Рис. 6. Изменение концентрации продуктов окисления лимонена в масле розового грейпфрута. Обозначения: $1-\alpha$-терпинеол, 2 - карвон, 3 - эпоксилимонен

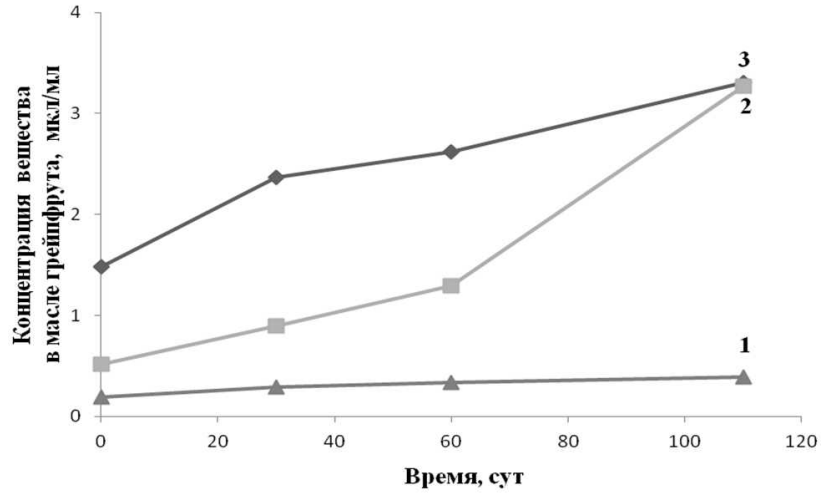

\section{Выводы}

Методом капиллярной газовой хроматографии обнаружено, что зависимость величины антиоксидантной активности эфирных масел кориандра, имбиря, семян тмина и розового грейпфрута от их концентрации непосредственно связана со скоростью изменения содержания основных веществ-антиоксидантов в составе изученных масел при длительном хранении на свету.

Наиболее резкую зависимость антиоксидантной активности от концентрации наблюдали для масла кориандра, а наименее резкую - для масла имбиря.

Низкие (менее 5 об. \%) концентрации масла розового грейпфрута не оказывали ингибирующего действия на окисление тест-альдегида.

\section{Список литературь}

1. Burt S. Essential oils: their antibacterial properties and potential applications in foods // Int. J. Food Microbiol. 2004. Vol. 94, N3. Pp. 223-253.

2. Hsu F.-L., Li W.-H., Yu C.-W., Hsieh Y.-C., Yang Y.-F., Liu J.-T., Shih J., Chu Y.-J., Yen P.-L., Chang S.-T., and Liao V. H.-C. In Vivo Antioxidant Activities of Essential Oils and Their Constituents from Leaves of the Taiwanese Cinnamomum osmophloeum // J. Agric. Food Chem. 2012. Vol. 60, N12. Pp. 3092-3097.

3. Özcan M.M., Arslan D. Antioxidant effect of essential oils of rosemary, clove and cinnamon on hazelnut and poppy oils // Food Chem. 2011. Vol. 129, N1. Pp. 171-174.

4. Wei A. and Shibamoto T. Antioxidant/Lipoxygenase Inhibitory Activities and Chemical Compositions of Selected Essential Oils // J. Agric. Food Chem. 2010. Vol. 58, N12. Pp. 7218-7225.

5. El-Ghorab H., Nauman M., Anjum F.M., Hussain S. and Nadeem M. A Comparative Study on Chemical Composition and Antioxidant Activity of Ginger (Zingiber officinale) and Cumin (Cuminum cyminum) // J. Agric. Food Chem. 2010. Vol. 58, N14. Pp. 8231-8237.

6. Ferreira F.D., Kemmelmeier C., Arrotéia C.C., da Costa C.L., Mallmann C.A., Janeiro V., Ferreira F.M.D., Mossini S.A.G., Silva E.L., Machinski M. Jr. Inhibitory effect of the essential oil of Curcuma longa L. and curcumin on aflatoxin production by Aspergillus flavus Link // Food Chem. 2013. Vol. 136, N2. Pp. 789-793.

7. Mitoshi, M. Kuriyama I., Nakayama H., Miyazato H., Sugimoto K., Kobayashi Y., Jippo T., Kanazawa K., Yoshida H., Mizushina Y. Effects of Essential Oils from Herbal Plants and Citrus Fruits on DNA Polymerase Inhibitory, Cancer Cell Growth Inhibitory, Antiallergic, and Antioxidant Activities // J. Agric. Food Chem. 2012. Vol. 60 , N45. Pp. 11343-11350.

8. Schilderman P., ten Vaarwerk F.J., Lutgerink J.T., Van der Wurff A., ten Hoor F., Kleinjans J.C. Induction of oxidative DNA damage and early lesions in rat gastro-intestinal epithelium in relation to prostaglandin $\mathrm{H}$ synthasemediated metabolism of butylated hydroxyanisole // Food Chem. Toxicol. 1995. Vol. 33. Pp. 99-109.

9. Witschi H., Morse C. Enhanced lung tumor formation in mice by dietary BHT // J. Natl. Cancer Inst. 1983. Vol. 71. Pp. 859-866.

10. Lee K.-G., Shibamoto T. Determination of antioxidant potential of volatile extracts isolated from various herbs and spices // J. Agric. Food Chem. 2002. Vol. 50, N17. Pp. 4947-4952.

11. Dorman H. J.D., Figueiredo A. C., Barroso J. G., Deans S.G. In vitro evaluation of antioxidant activity of essential oils and their components // Flavour Fragr. J. 2000. Vol. 15. Pp. 12-16.

12. Lee K.-G., Shibamoto T. Antioxidant properties of aroma extract isolated from clove buds [Syzygium aromaticum (L.) Merr. et Perry] // Food Chem. 2001. Vol. 74, N4. Pp. 443-448.

13. Kahkonen M.P., Hopia A.I., Vuorela H. J., Rauha J.-P., Pihlaja K., Kujala T. S., Heinonen M. Antioxidant Activity of Plant Extracts Containing Phenolic Compounds // J. Agric. Food Chem. 1999. Vol. 47, N10. Pp. 3954-3962. 
14. Areias F., Valentao P., Andrade P.B., Ferreres F., Seabra R.M. Flavonoids and Phenolic Acids of Sage: Influence of Some Agricultural Factors // J. Agric. Food Chem. 2000. Vol. 48, N12. Pp. 6081-6084.

15. Ruberto G., Baratta M.T. Antioxidant activity of selected essential oil components in two lipid model systems // Food Chem. 2000. Vol. 69, N2. Pp. 167-174.

16. Cabrera A.C., Prieto J.M. Application of artificial neural network to the prediction of the antioxidant activity of essential oils in two experimental in vitro models // Food Chem. 2010. Vol. 118, N1. Pp. 141-146.

17. Samusenko A.L. Comparative evaluation of antioxidant properties of spice-aromatic plant essential oils // Oxidation Communications. 2008. Vol. 31, N2. Pp. 275-284.

18. Samusenko A.L. Investigation of antioxidant activity of essential oils from lemon, pink grapefruit, coriander, clove and its mixtures by capillary gas chromatography // Oxidation Communications. 2008. Vol. 31, N3. Pp. 519-526.

19. Jennings W., Shibamoto T. Qualitative Analysis of Flavor and Fragrance Volatiles by Glass Capillary Gas Chromatography. New York; London; Sydney; Toronto; San Francisco, 1980. 472 p.

20. Lee K.G., Shibamoto T. Determination of antioxidant potential of volatile extracts isolated from various herbs and species // J. Agric. Food Chem. 2002. Vol. 50, N17. Pp. 4947-4952.

21. Lee K.G., Shibamoto T. Inhibition of malonaldehyde formation from blood plasma oxidadation by aroma extracts and aroma components isolated from clove and eucalyptus // Food and Chem. Toxicol. 2001. Vol. 39, N12. Pp. 1199-1204.

22. Yanagimoto K., Ochi H., Lee K.G., Shibamoto T. Antioxidative activities of volatile extracts from green tea, oolong tea, and black tea // J. Agric. Food Chem. 2003. Vol. 51, N25. Pp. 7396-7401.

23. Samusenko A.L. Influence of individual components of essential oils and flavorings on citral oxidation // Oxidation Comm. 2008. Vol. 31, N3. Pp. 511-518

Поступило в редакичию 15 января 2014 г.

Samusenko A.L. INVESTIGATION OF DEPENDENCE OF ANTIOXIDANT ACTIVITY OF ESSENTIAL OILS FROM CORIANDER, GINGER, SEEDS OF CARAWAY AND PINK GRAPEFRUIT ON OIL CONCENTRATION IN THE SYSTEM BY CAPILLARY GAS-LIQUID CHROMATOGRAPHY

N.M. Emanuel Institute of Biochemical Physics RAS, Kosigina st., 4, Moscow, 119991 (Russia),

e-mail: Samusenko.alexey@ rambler.ru

In recent time the biological activity of essential oils from spicy-aromatic herbs, including the antioxidant one, have been evaluated in numerous studies. Earlier we have demonstrated high antioxidant activity of the oils contained monoterpenes, such as $\gamma$-terpinene and $\alpha$-terpinolene, sesquiterpenes (zingeberene and $\beta$-caryofillene) and citral. However the concentration value of oils in the «aldehyde - essential oil» system was excessively high and the investigation of various concentrations was not carried out by us. The goal of this work was studying of the influence of oil concentration on antioxidant activity value for selected essential oils and correlation of the obtained data with a change of main antioxidants in the composition of the essential oils under study. The antioxidant properties of the essential oils from coriander

(Coriandrum sativum L.), ginger (Zingiber officinale L.), seeds of caraway (Carum carvi) and pink grapefruit (Citrus paradisi) have been studied in a wide interval of oil concentrations by capillary gas - liquid chromatography, using an aldehyde/carboxylic acid assay. Trans-2-hexenal was selected to serve as the test substance. The dependence of oil antioxidant activity on its concentration was found to be closely connected with a rate of content change of main antioxidants in the composition of the essential oils under study at prolonged exposure to light.

It was noted that the activity values of the main components of the studied oils had a clear impact on the concentration dependence of antioxidant activity of oils in general. It was observed the strongest dependence «antioxidant activity - oil concentration» for coriander oil, while ginger oil possessed the weakest one. The low concentrations of oil from pink grapefruit did not inhibit the aldehyde oxidation.

Keywords: spicy-aromatic herbs, essential oils, antioxidant activity, capillary gas chromatography. 


\section{References}

1. Burt S. Int. J. Food Microbiol., 2004, vol. 94, no. 3, pp. 223-253.

2. Hsu F.-L., Li W.-H., Yu C.-W., Hsieh Y.-C., Yang Y.-F., Liu J.-T., Shih J., Chu Y.-J., Yen P.-L., Chang S.-T., Liao V. H.-C. J. Agric. Food Chem., 2012, vol. 60, no. 12. Pp. 3092-3097.

3. Özcan M.M., Arslan D. Food Chem., 2011, vol. 129, no. 1, pp. 171-174.

4. Wei A., Shibamoto T. J. Agric. Food Chem., 2010, vol. 58, no. 12, pp. 7218-7225.

5. El-Ghorab H., Nauman M., Anjum F.M., Hussain S., Nadeem M. J. Agric. Food Chem., 2010, vol. 58, no. 14. pp. 8231-8237.

6. Ferreira F.D., Kemmelmeier C., Arrotéia C.C., da Costa C.L., Mallmann C.A., Janeiro V., Ferreira F.M.D., Mossini S.A.G., Silva E.L., Machinski M. Jr. Food Chem., 2013, vol. 136, no. 2, pp. 789-793.

7. Mitoshi, M. Kuriyama I., Nakayama H., Miyazato H., Sugimoto K., Kobayashi Y., Jippo T., Kanazawa K., Yoshida H., Mizushina Y. J. Agric. Food Chem., 2012, vol. 60, no. 45, pp. 11343-11350.

8. Schilderman P., ten Vaarwerk F.J., Lutgerink J.T., Van der Wurff A., ten Hoor F., Kleinjans J.C. Food Chem. Toxicol., 1995, vol. 33, pp. 99-109.

9. Witschi H., Morse C. J. Natl. Cancer Inst., 1983, vol. 71, pp. 859-866.

10. Lee K.-G., Shibamoto T. J. Agric. Food Chem., 2002, vol. 50, no. 17, pp. 4947-4952.

11. Dorman H.J.D., Figueiredo A.C., Barroso J.G., Deans S.G. Flavour Fragr. J., 2000, vol. 15, pp. 12-16.

12. Lee K.-G., Shibamoto T. Food Chem., 2001, vol. 74, no. 4, pp. 443-448.

13. Kahkonen M.P., Hopia A.I., Vuorela H. J., Rauha J.-P., Pihlaja K., Kujala T. S., Heinonen M. J. Agric. Food Chem., 1999, vol. 47, no. 10, pp. 3954-3962.

14. Areias F., Valentao P., Andrade P.B., Ferreres F., Seabra R.M. J. Agric. Food Chem., 2000, vol. 48, no. 12, pp. 6081-6084.

15. Ruberto G., Baratta M.T. Food Chem., 2000, vol. 69, no. 2, pp. 167-174.

16. Cabrera A.C., Prieto J.M. Food Chem., 2010, vol. 118, no. 1, pp. 141-146.

17. Samusenko A.L. Oxidation Communications, 2008, vol. 31, no. 2, pp. 275-284.

18. Samusenko A.L. Oxidation Communications, 2008, vol. 31, no. 3, pp. 519-526.

19. Jennings W., Shibamoto T. Qualitative Analysis of Flavor and Fragrance Volatiles by Glass Capillary Gas Chromatography. New York; London; Sydney; Toronto; San Francisco, 1980. 472 p.

20. Lee K.G., Shibamoto T. J. Agric. Food Chem., 2002, vol. 50, no. 17, pp. 4947-4952.

21. Lee K.G., Shibamoto T. Food and Chem. Toxicol., 2001, vol. 39, no. 12, pp. 1199-1204.

22. Yanagimoto K., Ochi H., Lee K.G., Shibamoto T. J. Agric. Food Chem., 2003, vol. 51, no. 25, pp. 7396-7401.

23. Samusenko A.L. Oxidation Comm., 2008, vol. 31, no. 3, pp. 511-518 
